\title{
Epileptic encephalopathy and atypical Rett syndrome with mutations in CDKL5: clinical and molecular characterization of two Brazilian patients
}

\author{
Encefalopatia epilética e síndrome de Rett atípica por mutações no gene CDKL5: caracterização \\ clínica e molecular de dois casos brasileiros
}

\author{
Érica Leitão Ermel', Lauriane Caroline Carneiro', Carolina Fischinger Moura de Souza², Ana Chrystina de \\ Souza Crippa ${ }^{3}$, Maria Teresa Vieira Sanseverino ${ }^{4}$, Salmo Raskin ${ }^{5}$ \\ ${ }^{1} \mathrm{MD}$, Faculdade Evangélica do Paraná, Curitiba PR, Brazil; \\ ${ }^{2} \mathrm{MD}$, Medical Genetic Service, Hospital de Clínicas de Porto Alegre RS, Brazil; \\ ${ }^{3} \mathrm{MD}$, PhD, Neurophysiologist, Neurology Division, Internal Medicine Department, Hospital de Clínicas, Universidade Federal do Paraná, Curitiba PR, Brazil; \\ ${ }^{4} \mathrm{MD}$, PhD, Medical Genetic Service, Hospital de Clínicas de Porto Alegre RS, Brazil; \\ ${ }^{5} \mathrm{MD}$, PhD, Group for Advanced Molecular Investigation (NIMA), Graduate Program in Health Science (PPGCS), Health and Biosciences School (ESB), \\ Pontifícia Universidade Católica do Paraná (PUCPR), Curitiba PR, Brazil. \\ Correspondence: Érica Leitão Ermel; Rua Weyner Junior Maciel Alves 320 / Condomínio Royal Golf; 86055-500 Londrina PR - Brasil; E-mail:ericaermels@yahoo.com.br \\ Conflict of interest: There is no conflict of interest to declare. \\ Received 20 March 2012; Received in final form 01 February 2013; Accepted 08 February 2013.
}

Mutations in the CDKL5 gene cause early onset epilepsy, infantile spasms with hypsarrhythmia on the electroencephalogram (EEG) and atypical Rett syndrome. Axial hypotonia, severe developmental delay and autistic spectrum disorder are also frequently found in patients with these mutations ${ }^{1}$.

Different epileptic manifestations were described in patients with mutations in the CDKL5 gene, including seizures with onset at the first six months of life, infantile spasms and myoclonic epilepsy, ${ }^{1,2}$

In 2007, the two first Brazilian patients with Rett syndrome and mutations in the MeCP2 gene were reported ${ }^{3}$. Here, we described the clinical condition and characterization of the two first Brazilian patients with CDKL5 mutations, including the first Brazilian case of atypical Rett related to abnormalities in this gene.

Both girls presented severe developmental delay, axial hypotonia, early onset seizures highly resistant to treatment and hypsarrhythmia. Case 2 also presented a Rett-like phenotype. A small mutation in one allele of exon 8 of the CDKL5 gene, c.549dupA, was found in Case 1, and, in Case 2, a mutation in the Xp22.3 locus detected by array-CGH deleted the whole CDKL5 gene in one allele.

In Case 1, an apparently normal development was reported until de age of two months, when the patient was affected by clonic partial evolving to generalized seizures. Case 2, like most cases related to abnormalities in this gene, presented developmental impairment and hypotonia described to be noticed since the first days of life, although the seizures onset occurred later compared to the average rate previously described, at six months ${ }^{1,4}$.

We observed in our patients the three-step epilepsy phenotype recently associated with CDKL5 mutations, both presenting refractory epilepsy with multifocal activity on the EEG, described to be associated to a more severe phenotype. A group of patients with a better outcome was also reported in the literature. In those, "honey-moon" periods, after anticonvulsants introduction, became permanent with complete absence of seizures, even though neurological condition and hypotonia

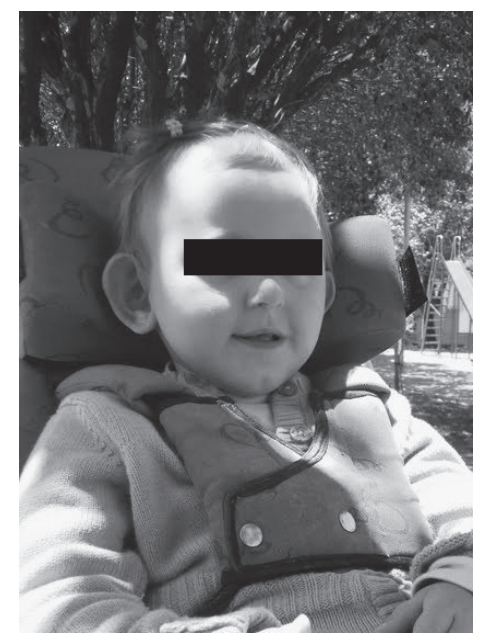

Figure. Patient 2, at three years and six months, presenting elongated skull and prominent ears. Array-CGH showed a 1,6Mb "de novo" deletion at Xp22.13, which included the whole CDKL5 and NHS genes in one allele. 
remained stable $e^{4}$ In Case 1 , progression to the late stages occurred despite the decrease in seizures frequency, at one year and eight months, with subsequent improvement of neurological condition.

No unique EEG pattern is observed in patients presenting CDKL5 mutations. Interictal EEG is usually normal at epilepsy onset, or shows background slowing, however focal and multifocal discharges were also previously described ${ }^{1,4}$. Posteriorly, a progressive deterioration with slowing of basal rhythm and disappearance of physiological features tend to occur, with subsequent development of epileptic encephalopathy ${ }^{4}$. In Case 1, the first EEG detected, besides background slowing, interictal activity in left temporal lobe, and, in Case 2, diffuse abnormalities in a normal background.

In Case 2 (Figure), the presence of Rett-like features, such as stereotypies, hyperventilation, bruxism and hand apraxia, in the absence of an early normal period due to the presence of seizures, is consistent with atypical Rett caused by CDKL5 mutations ${ }^{5}$.

This study reinforces the previously reported phenotype related to mutations in the CDKL5 gene. Epilepsy with onset within six months of life, especially in the presence of infantile spasms, in females with psychomotor impairment in the first months and hypotonia, strongly suggests screening for mutations in this gene.

\section{References}

1. Archer H, Evans J, Edwards S, et al. CDKL5 mutations cause infantile spasms, early onset seizures, and severe mental retardation in female patients. J Med Genet 2006;43:729-734.

2. Buoni S, Zannolli R, CalamariaV, et al. Myoclonic encephalopathy in the CDKL5 gene mutation. Clin Neurophysiol 2006;117:223-227.

3. Stachon A, Assumpção FB Jr, Raskin S. Rett syndrome: clinical and molecular characterization of two Brazilian patients. Arq Neuropsiquiatr 2007;65:36-40.

4. Bahi-Buisson N, Kaminska A, Boddaert N, et al. The three stages of epilepsy in patients with CDKL5 mutations. Epilepsia 2008;49:1027-1037.

5. Hanefeld F. The clinical pattern of the Rett syndrome. Brain Dev $1985 ; 7: 320-325$ 